\title{
Cusp fusion pattern in bicuspid aortic valve disease predicts severity of aortic flow abnormalities
}

\author{
Malenka M Bissell ${ }^{1 *}$, Aaron T Hess ${ }^{1}$, Steffan J Glaze ${ }^{1}$, Alex Pitcher ${ }^{1}$, Matthew D Robson ${ }^{1}$, Alex J Barker², \\ Saul Myerson ${ }^{1}$, Stefan Neubauer ${ }^{1}$
}

From 16th Annual SCMR Scientific Sessions

San Francisco, CA, USA. 31 January - 3 February 2013

\section{Background}

Bicuspid aortic valve disease (BAV) is associated with aortic dilation. We examined whether cusp fusion pattern altered the severity of aortic flow abnormalities and ascending aortic wall shear stress (WSS).

\section{Methods}

We prospectively enrolled 80 patients (51 with rightleft-coronary-cusp fusion pattern [RL-BAV] and 29 with right-non-coronary-cusp fusion pattern [RN-BAV]), and 27 healthy volunteers (HV) with a mean age across groups of $42 \pm 16$ years. Time-resolved 3-dimensional flow-sensitive magnetic resonance imaging was used to quantify flow abnormalities and local distribution of WSS in the ascending aorta. The amount of helical blood flow was quantified using the planar fluid circulation measure. 'Normal' flow patterns in HV involved a very mild right or left-handed helix (mean planar fluid circulation $3.2 \pm 2 \mathrm{SD}$ : -5 to $\left.+11 \mathrm{~mm}^{2} / \mathrm{s}\right)$. Abnormal right-handed helical flow pattern was defined as planar fluid circulation $>11 \mathrm{~mm}^{2} / \mathrm{s}$ and abnormal left-handed helical flow pattern as $<-5 \mathrm{~mm}^{2} / \mathrm{s}$. Complex flow was visually defined as disintegration of the helical flow pattern.

\section{Results}

Both BAV groups showed predominantly abnormal flow, but with significant differences. In the RL-BAV group, $10 \%$ had normal flow patterns, $80 \%$ had abnormal righthanded flow and $10 \%$ had complex flow. There was no left-handed flow. The RN-BAV group showed more

'Oxford Centre for Clinical Magnetic Resonance Research, University of Oxford, Oxford, UK

Full list of author information is available at the end of the article severe flow abnormalities in general, with no normal flow, a mainly right-handed flow pattern in 66\%, complex flow in $24 \%$ and left-handed flow in $10 \%$. Circumferentially averaged systolic WSS (WSSsyst) increased with the severity of helical flow abnormality: $0.58 \pm 0.20$ $\mathrm{N} / \mathrm{m}^{2}$ vs. $0.83 \pm 0.27 \mathrm{~N} / \mathrm{m}^{2}$ vs. $1.15 \pm 0.35 \mathrm{~N} / \mathrm{m}^{2}$ in normal, right-handed and left-handed flow respectively. WSSsyst in complex flow patterns was lower than helical patterns $\left(0.72 \pm 0.26 \mathrm{~N} / \mathrm{m}^{2}\right)$, implying that the lack of organised helix in complex flow reduces the WSS, but still not to normal.

To determine the impact of cusp fusion pattern on aortic size, flow disturbance and WSS independent of the flow pattern, we compared BAV patients with the commonest flow pattern (right-handed flow). RN-BAV had larger ascending aortic diameters adjusted for body surface area (1.95 vs. $\left.1.75 \mathrm{~cm} / \mathrm{m}^{2}, \mathrm{p}=0.04\right)$ and higher planar fluid circulation value ( 36.5 vs. $26.6 \mathrm{~mm} 2 / \mathrm{s}$, $\mathrm{p}=0.009$ ) compared to RL-BAV. Both subgroups had similar WSSsyst, high anterior total WSS values and normal posterior total WSS. Splitting the total WSS into its components, RN-BAV had a higher in-plane WSS (0.62 vs $\left.0.45 \mathrm{~N} / \mathrm{m}^{2}, \mathrm{p}=0.006\right)$.

\section{Conclusions}

RN-BAV showed more severe flow abnormalities and larger ascending aortas. These findings are the first potentially causative indication that cusp fusion pattern is important in determining adverse aortic outcome.

\section{Funding}

This study is funded by the British Heart Foundation.

(C) 2013 Bissell et al; licensee BioMed Central Ltd. This is an Open Access article distributed under the terms of the Creative Commons 


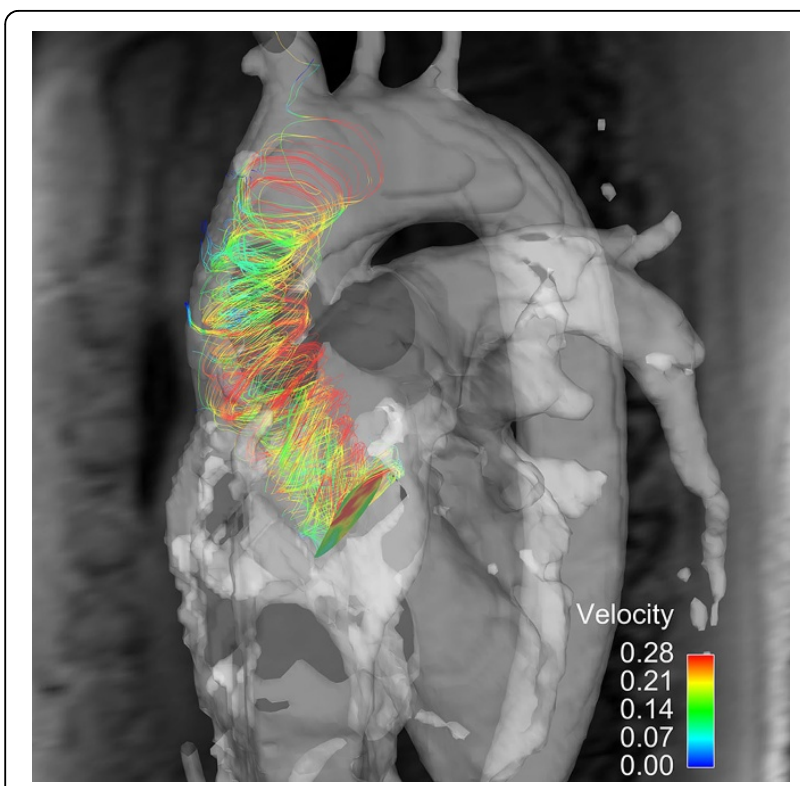

Figure 1 Right-handed helical flow pattern in bicuspid aortic valve disease.

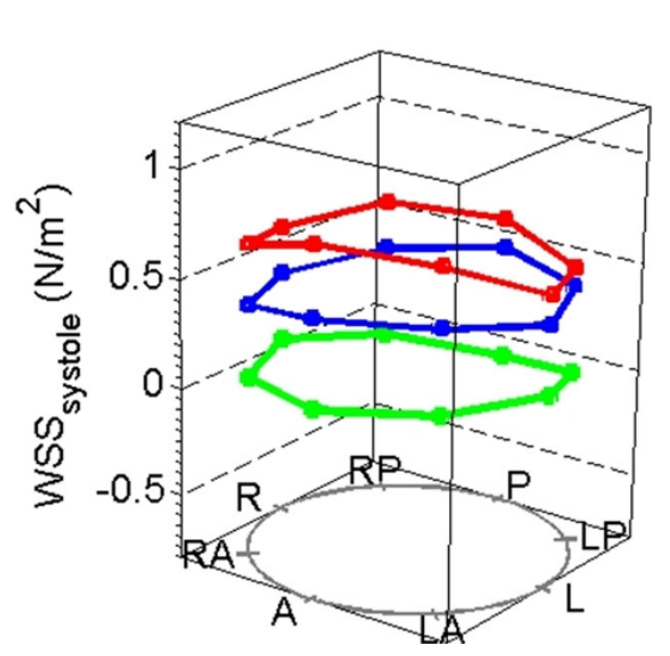

Figure 2 In-plane wall shear stress patterns in the ascending aorta.

\section{Author details}

${ }^{1}$ Oxford Centre for Clinical Magnetic Resonance Research, University of Oxford, Oxford, UK. ${ }^{2}$ Departments of Radiology and Biomedical Engineering, Northwestern University Feinberg School of Medicine, Chicago, IL, USA.

Published: 30 January 2013

\section{doi:10.1186/1532-429X-15-S1-069}

Cite this article as: Bissell et al:: Cusp fusion pattern in bicuspid aortic valve disease predicts severity of aortic flow abnormalities. Journal of Cardiovascular Magnetic Resonance 2013 15(Suppl 1):O69.

\section{Submit your next manuscript to BioMed Central} and take full advantage of:

- Convenient online submission

- Thorough peer review

- No space constraints or color figure charges

- Immediate publication on acceptance

- Inclusion in PubMed, CAS, Scopus and Google Scholar

- Research which is freely available for redistribution 